\title{
A Priori Determination of Track Modulus Based On Elastic Solutions
}

\author{
Bose, Tulika; Levenberg, Eyal \\ Published in: \\ K S C E Journal of Civil Engineering
}

Publication date:

2020

Document Version

Peer reviewed version

Link back to DTU Orbit

Citation (APA):

Bose, T., \& Levenberg, E. (2020). A Priori Determination of Track Modulus Based On Elastic Solutions. K S C E Journal of Civil Engineering, 24, 2939-2948.

\section{General rights}

Copyright and moral rights for the publications made accessible in the public portal are retained by the authors and/or other copyright owners and it is a condition of accessing publications that users recognise and abide by the legal requirements associated with these rights.

- Users may download and print one copy of any publication from the public portal for the purpose of private study or research.

- You may not further distribute the material or use it for any profit-making activity or commercial gain

- You may freely distribute the URL identifying the publication in the public portal

If you believe that this document breaches copyright please contact us providing details, and we will remove access to the work immediately and investigate your claim 


\section{KSCE Journal of Civil Engineering A Priori Determination of Track Modulus Based On Elastic Solutions --Manuscript Draft--}

Manuscript Number:
Full Title:

Article Type:

Corresponding Author:

KSCE-D-19-00372R2

A Priori Determination of Track Modulus Based On Elastic Solutions

Research Paper

TULIKA BOSE

Danmarks Tekniske Universitet

Copenhagen, DENMARK

\section{Corresponding Author Secondary} Information:

Corresponding Author's Institution:

Danmarks Tekniske Universitet

Corresponding Author's Secondary Institution:

First Author:

TULIKA BOSE, PhD student

First Author Secondary Information:

Order of Authors:

TULIKA BOSE, PhD student

EYAL LEVENBERG, Associate Professor

Order of Authors Secondary Information:

Funding Information:

Abstract:

Response to Reviewers:
The standard approach for modeling railway tracks idealizes the rails as two infinite beams, each supported by a continuous spring foundation. The foundation is characterized by a track modulus that embodies all components and materials underlying each rail as well as any cross-rail interaction. Track modulus is considered a basic parameter governing the field performance of tracks. Therefore, a priori determination of track modulus is needed in design of traditional railways, as well as in evaluating the performance-potential of non-traditional track solutions. In this study, a new method was suggested for a priori track modulus determination based on elastic solutions. Specifically sought were closed-form analytical formulations that could be representative and tractable. In this connection, a 3-D track model was developed, wherein: rail-pads were considered as linear springs, sleepers as finite beams, and all underlying soil-like materials as a homogenous half-space. Ultimately, track modulus was determined by linking calculations in the 3-D model and the standard model. This was done by requiring equal maximal displacement as well as identical load distribution along the rail under the weight of a single railcar axle. The method was illustrated considering a wide set of values for the different model parameters. The calculated results are comparable in magnitude and exhibit similar sensitivities to the input parameters as reported in field studies or as derived from elaborate numerical schemes.

To address this comment, a new figure (Figure 7) has been added to the paper showing a comparison of track modulus values, calculated using the current method and with the reference studies. The Figure has also been referred to in the text in Chapter 6 as:

"Specifically, it was possible to closely reproduce the track modulus results shown in Figure 4 in Selig and Li for the entire range of subgrade moduli, fastener stiffnesses, and tie spacings - when assuming ballast and subballast moduli were same as subgrade to accommodate homogenous half-space assumption. Also, the results are within the range of track modulus values observed in field studies (Norman et al. 2004; Narayanan et al. 2004). A graphical depiction of these comparisons is provided in Figure 7.

The reference (Tzanakakis, K. (2013) position has been rectified.

New Figure 7 and caption: 


\section{Author Comments:}

Dear Editor,

Thank you for your comments. The changes have been addressed and the revised manuscript has been uploaded for your kind consideration.

Looking forward to your esteemed decision.

Sincerely,

Tulika Bose and Eyal Levenberg 
Railroad Engineering

\title{
A Priori Determination of Track Modulus Based On Elastic Solutions
}

\author{
Tulika Bose [Corresponding author] \\ PhD student \\ Department of Civil Engineering, Technical University of Denmark \\ Nordvej, Building 119 \\ Kgs. Lyngby 2800, Denmark \\ Email: tulbo@byg.dtu.dk \\ Eyal Levenberg \\ Associate Professor \\ Department of Civil Engineering, Technical University of Denmark \\ Nordvej, Building 119 \\ Kgs. Lyngby 2800, Denmark \\ Tel: +45 45251907 \\ Email: eylev@byg.dtu.dk
}


Keywords: Track Modulus, Railway, Elasticity, Track stiffness, Rail track modeling. 


\section{Introduction}

Winkler's (1867) hypothesis of subgrade reaction is widely practiced for design and analysis of soil-coupled constructions such as: (i) pile and raft foundations (Hemsley 2000), (ii) concrete pavements (Westergaard, 1948; Ioannides, 2006), (iii) buried pipes (Rajani et al., 1996; Klar et al., 2005), and (iv) tunnel linings (Wood, 1975; Lee et al., 2001; Mair, 2008). Essentially, this hypothesis is a radical mathematical simplification of actual soil behavior; it does not directly represent any basic material property. Because of this, problem-specific methods or guidelines are needed to suitably determine subgrade reaction values for subsequent structural evaluation. In an early contribution, Biot (1937) offered such guidelines for the case of an infinite beam resting on an elastic half-space and loaded by a concentrated force. The development was founded on theoretical arguments, and was based on requiring equivalency of maximal beam moments. Vesić (1961) extended Biot's work to include beams of finite length. The proposed guidelines were based on theoretical considerations reinforced by experimental evidence. They also utilized maximal moment as basis for equivalency. Determination methods of subgrade reaction for foundation design were proposed by Terzaghi (1955) after combining full-scale field experience and theoretical considerations. Similarly, full-scale experiments and theoretical considerations were employed to guide practitioners on determining subgrade reaction for slab-on-grade constructions (Vesic and Saxena, 1969; Khazanovich et al., 2001; Setiadji and Fwa, 2009; Daloglu and Vallabhan, 2000).

A mathematically equivalent concept to subgrade reaction - called 'track modulus' is commonly utilized within the field of railway engineering (Selig and Li 1994). In words, track modulus expresses the supporting force per unit length of an infinite rail per unit vertical rail displacement. The concept serves as a basic input parameter for: (i) calculating rail bending stresses and deflections under the weight of railcar axles (Sadeghi and Barati, 2010; Hay, 1982; AREMA Manual 2006; Kerr, 2003; Selig and Waters, 1994), (ii) analysis of vibrations caused by vehicle dynamics (Newton and Clark, 1979), and (iii) assessing overall in-service track quality (Ebersöhn et al., 1993; Read et al., 1994; Roghani and Hendry, 2017). Unlike soilcoupled constructions, track modulus embodies the continuous support offered to a rail by discrete track components, e.g., rail-pads, sleepers, under-sleeper pads, and ballast mats, as well as by soil-like materials, 
e.g., ballast, sub-ballast, and subgrade. This means that track modulus is governed by a large set of attributes, i.e., material properties, component dimensions, interconnectivity, etc. Perhaps because of this intricacy the vast majority of existing methods for determining track modulus rely on field measurements (Kerr, 2000; Norman et al., 2004; Lu et al., 2008; Zakeri and Abbasi, 2012;Nafari et al,. 2017; Narayanan et al., 2004).

The idea of track stiffness, taken to mean the point-load required to produce a unit deflection of the rail (at the location where the load is applied), is often employed for evaluating the quality of existing tracks (Tzanakakis, 2013). In effect, whenever assuming a beam on Winkler model for the rail, track stiffness and track modulus are directly linked. However, while track stiffness encapsulates all track components to provide some global stiffness, track modulus is only focused on the support offered to the rail. The advantage of so doing is related to the fact that rail flexural properties are engineered and well defined whereas the support offered to the rail may vary widely; thus, track modulus is closely linked to the sources governing the track quality.

A priori determination of track modulus can be attained with realistic and representative track models that are able to accept basic material properties as input. Such determination is needed in newdesign and rehabilitation-design of railways, e.g., for guiding the selection of components and materials; it is equally important when evaluating the performance-potential of non-traditional track solutions for which limited field experience exists (if any). Nonetheless, only a handful of studies were specifically dedicated to this task.

The GEOTRACK program (Adegoke et al., 1979; Chang et al., 1980), successor of the MULTA code (Prause and Kennedy, 1977), represents one of the first efforts to develop an elaborate and realistic track model. In the program, the rail and sleepers were considered as Euler-Bernoulli beams of finite length, rail-pads were represented by discrete linear springs, and all soil-like layers (ballast, sub-ballast, and subgrade) were represented by a stratified elastic half-space. The total model size was limited to eleven sleepers supported on the surface of the layered half-space, jointly carrying two rails. As means of simulating the weight action of a railcar axle, vertical point-loads were applied to the rails, just above the 

formulation. In turn, the corresponding stress distributions at the surface of the half-space were approximated as circular loads (Burmister, 1945). Ultimately, by means of a stiffness matrix formulation, the displacements at the interaction points between all model elements were matched. The GEOTRACK program was not explicitly designed for performing a priori determination of track modulus. Nonetheless, it was applied for this purpose (Stewart, 1985), with reported reasonable agreement between calculated and field-measured track modulus values. To achieve this the elastic properties of all model components were assumed, and track modulus was determined solely based on a criterion of maximal rail displacement, i.e., by equating maximal rail displacement in GEOTRACK and in the infinite beam on a continuous spring model. One drawback of this approach is the incompatibility in the distribution of vertical forces along the track in the sleeper locations - resulting in a mismatch of bending stress distribution in the rails. Regardless, the GEOTRACK program is neither accessible nor handy at this time; it is incompatible with modern computing platforms and non-upgradable - available only in compiled form (Mishra et al., 2016).

A priori determination of track modulus was specifically targeted by Cai et al. (1994) The work commenced by analyzing a finite length beam representing a single sleeper, supported on a Winkler foundation (representing the entire track structure below the sleeper), and loaded by two equal forces representing loading at the rail seats. The sought track modulus was calculated based on the displacement of the finite beam under one of the forces, taking into account the added flexibility due to rail-pad and sleeper compressibility (jointly represented as an additional discrete spring in series). The subgrade reaction offered to the finite beam was obtained from an approximate formula (Galin, 1943). This formula expresses the interaction between a finite beam and a linear elastic (homogenous) half-space based on the assumption that the beam's width tends to zero. Steinbrenner's (1936) formula was also suggested in this study for calculating a single 'effective' Young's modulus from a layered half-space (representing ballast, subballast, subgrade, and deeper soil layers). The main limitation of the work comes from the analysis of a single sleeper. Doing so disregards the effect of adjacent sleepers, and therefore results in overestimation of the track modulus. Other limitations include representing the sleeper as a zero-width finite beam, and 


\section{Method Overview (a main section)}

The standard approach for modeling railway tracks idealizes the rails as two weightless separate infinite beams (IBs), each individually supported on a continuous spring foundation; this model is graphically shown in Fig. 1(a). The figure also includes a Cartesian coordinate system where the $X$-axis is oriented along the IBs, the $Y$-axis is transverse to the IBs, and the $Z$-axis points vertically downward. As can be seen, the two IBs are simultaneously loaded by point forces with intensity $P_{Z}$ representing (jointly) a single railcar axle. The foundation is characterized by a track modulus with spring constant $k_{Z}$ that embodies all components and materials underlying each rail as well as any cross-rail interaction.

To facilitate a priori determination of $k_{Z}$, a 3-D elastic quasi-static track model is developed, comprising all components and materials below the rail that govern the track modulus. It consists of an 
equidistant array of sleepers (spacing denoted by $s$ ) modeled as Euler-Bernoulli finite beams (FBs) with uniform cross-section. Each FB is identified by an index $n$, going from positive to negative, with the zeroth FB located at the center of the 3-D model. The FBs are supported by an underlying elastic half-space (HS) that is linear, homogenous and isotropic. The HS represents all soil-like materials, which for a traditional track includes: ballast (excluding crib and shoulder ballast), sub-ballast, and deeper soil layers; for a nontraditional track the soil-like materials may also include: asphalt concrete, Portland cement concrete, stabilized ballast, etc. The exclusion of materials from in-between and along the sides of the finite beams is justified given their marginal effect (if any) on vertical track responses. Fig. 1(b) shows a part of this model consisting of seven FBs, with the model sides and bottom truncated for visual clarity. The two dark shaded patches seen at the top of each FB represent rail-pad locations; each modeled as a linear discrete spring (DS).

Fig. 1(b) shows that the DSs in the 3-D model are directly loaded by forces with intensities $S_{Z}^{n}$ 's. These forces are spring reactions calculated in the standard model with an assumed $k_{Z}$, after converting the 'continuous' springs into individual ones (also with spacing $s$ ). For this purpose, the two models are aligned such that the position of $P_{Z}$ in Fig. 1(a) corresponds to the center of the 3-D model in Fig. 1(b). The relative size of the arrows schematically indicate the difference in force intensities applied on top of individual DSs. Considering that all 3-D model parameters are known, the displacement at the top of the zeroth DS (on either side) is calculated quasi-statically due to the simultaneous application of all $S_{Z}^{n}$,s. This displacement is composed of the shortening of the zeroth DS and the surface deflection of the HS directly below it. In this calculation, it is assumed that the FBs are incompressible, and that they remain in frictionless contact with the HS. Therefore, as part of the calculation, it is necessary to resolve the contact stresses at the interface of the FBs and underlying HS. The frictionless contact assumption means that FBs are fully bonded to the HS on which they are supported - allowing for full transfer of stresses in the vertical direction, without allowing shear stresses to develop at the bonding interface. This 
neglect of interface shear stresses is justified given their second order effect, and given the focus on track modulus.

Ultimately, a representative track modulus is determined by manipulating the assumed $k_{Z}$ until a match is attained between the calculated displacement at the top of the zeroth DS and the maximal IB displacement from the standard track model. Thus, an intimate and close connection is established between the 3-D model and the standard model accounting not only for maximum displacement equivalence but also for equivalence in the longitudinal load spreadability, i.e., identical moment distribution along the rail. More details on the method and underlying calculations are provided in what follows.

\section{Elastic Solutions (a main section)}

Two closed-form independent elastic solutions are presented in this section. The first analyzes a FB subjected to two line-loads of equal intensity (i.e., a straight track) and a non-uniform support reaction. The line-loads represent rail-seat forces distributed over the length of rail-pads, and the non-uniform support reaction represents an interaction with a HS. The second elastic solution deals with the surface deflection of a HS that is loaded over a rectangular stress patch. Then after, both solutions are combined to analyze the interaction at the FB-HS interface with the aim of resolving the contact stress distribution between a sleeper and its supporting medium. Ultimately, these solutions are applied to determine the surface deflection of the HS under the action of several $S_{Z}^{n}$,s acting simultaneously (refer to Fig. 1(b)).

\subsection{Solution1: Analysis of a FB}

A FB of length $L$ with free ends is shown in Fig. 2; a 3-D Cartesian coordinate system is also included in the Figure with similar orientation as in Fig. 1. Here, the origin is located at the leftmost end of the FB, with the $Z$-axis pointing vertically downward, the $Y$-axis pointing along the length of the beam, and the $X$-axis oriented perpendicular to the $Y Z$ plane. The beam's elastic modulus is $E_{F B}$, and moment of inertia about the $X$-axis is $I_{X, F B}$. The beam is symmetrically loaded by two line-loads of equal magnitude $w_{Z}$ (units of 
force/length), acting over a length $L_{2}$ at a distance of $L_{1}$ from the beam ends. It is also loaded at the bottom by a segmented array of opposing line-loads representing a support reaction. There are 12 such segments of equal length ( $L / 12$ ), numbered from left to right; each with uniform magnitude. The overall shape of the support reaction is variable, governed by the values of five independent unitless coefficients denoted as $a_{i}$ 's. These unitless coefficients represent a reaction intensity relative to unity, i.e., if all five $a_{i}$ 's equal unity then the support reaction becomes uniform across the entire length of the beam. In the interest of clarity, conditions of symmetry have not been invoked in the FB analysis.

The governing differential equation of the FB is:

$\frac{d^{4} u_{Z, F B}(y)}{d y^{4}}=\frac{p_{Z}(y)-r_{Z}(y)}{E_{F B} I_{X, F B}}$

wherein, $u_{Z, F B}(y)$ denotes the displacement of the FB along $Z$-axis direction, $p_{Z}(y)$ represents the loading that acts from the top, $r_{Z}(y)$ is the segmented bottom support reaction, and $y$ identifies the calculation location along the FB, i.e., $0 \leq y \leq L$. Utilizing the Heaviside function $H($ ), and enforcing equilibrium considerations, these are expressed as follows:

$$
\begin{aligned}
& p_{Z}(y)=w_{Z}\left(\begin{array}{l}
H\left(2 y-2 L_{1}+L_{2}\right)-H\left(2 y-2 L_{1}-L_{2}\right)+ \\
H\left(2 y-2 L+2 L_{1}+L_{2}\right)-H\left(2 y-2 L+2 L_{1}-L_{2}\right)
\end{array}\right) \\
& r_{Z}(y)=\frac{24 w_{Z} L_{2}}{L a_{T}}\left(\begin{array}{l}
\sum_{k=1}^{4}\left(a_{k}-a_{k+1}\right)(H(y-k L / 12)-H(y-L+k L / 12)) \\
+\left(a_{5}-1\right)(H(y-5 L / 12)-H(y-7 L / 12))-a_{1}
\end{array}\right)
\end{aligned}
$$

wherein $a_{T}=2\left(a_{1}+a_{2}+a_{3}+a_{4}+a_{5}+1\right)$.

Eqs. (2) and (3) are inserted into Eq. (1), and a solution for $u_{Z, F B}(y)$ is obtained after applying the boundary conditions of zero shear force and zero bending moment at beam ends as well as zero slope at the beam center. The result is:

$$
u_{Z, F B}(y)=\frac{w_{Z}}{E_{F B} I_{X, F B}}\left(\frac{D_{1}}{24}+\frac{L_{2} D_{2}}{L a_{T}}\right)-y D_{3}+D_{4}
$$


where,

$$
\begin{aligned}
& D_{1}=\left(\begin{array}{l}
\left(y-L+L_{1}+L_{2} / 2\right)^{4} H\left(y-L+L_{1}+L_{2} / 2\right)-\left(y-L+L_{1}-L_{2} / 2\right)^{4} H\left(y-L+L_{1}-L_{2} / 2\right) \\
+\left(y-L_{1}+L_{2} / 2\right)^{4} H\left(y-L_{1}+L_{2} / 2\right)-\left(y-L_{1}-L_{2} / 2\right)^{4} H\left(y-L_{1}-L_{2} / 2\right)
\end{array}\right) \\
& D_{2}=\left(\begin{array}{l}
\left.\sum_{k=1}^{4}\left(a_{k}-a_{k+1}\right)\left((y-k L / 12)^{4} H(y-k L / 12)-(y-L+k L / 12)^{4} H(y-L+k L / 12)\right)\right) \\
+\left(a_{5}-1\right)\left((y-5 L / 12)^{4} H(y-5 L / 12)-(y-7 L / 12)^{4} H(y-7 L / 12)\right)-a_{1} y^{4}
\end{array}\right) \\
& D_{3}=\frac{9 w_{Z}}{432 E_{F B} I_{X, F B}}\left(\begin{array}{l}
\left(L-2 L_{1}+L_{2}\right)^{3}\left(H\left(L-2 L_{1}+L_{2}\right)+H\left(2 L_{1}-L_{2}-L\right)\right) \\
-\left(L-2 L_{1}-L_{2}\right)^{3}\left(H\left(L-2 L_{1}-L_{2}\right)+H\left(2 L_{1}+L_{2}-L\right)\right) \\
-\frac{L^{2} L_{2}}{9 a_{T}}\left(91 a_{1}+61 a_{2}+37 a_{3}+19 a_{4}+7 a_{5}+1\right)
\end{array}\right)
\end{aligned}
$$

and $D_{4}$ is a free constant accounting for rigid body displacement.

\subsection{Solution 2: HS Loaded over a Rectangular Stress Patch}

A linear elastic half-space, characterized by Young's modulus $E_{H S}$ and Poisson's ratio $v_{H S}$, is loaded at the surface by a uniform vertical stress with intensity $q_{Z}$ acting over a rectangular area of dimensions $b \times a$ . This situation is shown in Fig. 3, which also includes a 3-D Cartesian coordinate system placed at the center of the patch; the $Z$-axis is pointing downward, and the $X$ and $Y$ axes are oriented parallel to the patch sides. The surface deflection of any point along the $Y$-axis due to the stress patch is denoted by $u_{Z, H S}^{p}(y)$. By integration of Boussinesq's point-load solution, the related expression is:

$u_{Z, H S}^{p}(y)=\frac{1-v_{H S}^{2}}{2 \pi E_{H S}} q_{Z} f(y)$

wherein,

$$
f(y)=(a+2|y|) \ln \frac{\left(f^{+}+b\right)\left(f^{-}+b\right)}{\left(f^{+}-b\right)\left(f^{-}-b\right)}+2 b \ln \frac{f^{-}+(a-2|y|)}{f^{+}-(a+2|y|)}
$$

and, 


$$
f^{ \pm}=\sqrt{(a \pm 2|y|)^{2}+b^{2}}
$$

\subsection{Interaction Analysis at the FB-HS Interface}

The two separate elastic solutions are hereafter combined to resolve the contact stress distribution below a single FB having width $b$ and supported by a HS. This means determination of the five $a_{i}$ 's as well as the rigid body displacement $D_{4}$. To achieve this, the displacement of the FB and the surface deflection of the HS are matched in the least-squares sense. Such matching represents a bonded yet frictionless contact area of dimension $L \times b$ between the two elastic bodies.

Based on the coordinate system defined in Fig. 2, and for a given FB loaded by an arbitrary $w_{Z}$, Eq. (4) is utilized to calculate $u_{Z, F B}(y)$ at $y=y_{j}=j L / J(j=0, \ldots, J)$, i.e., at $J+1$ equidistant points within $L$. Concurrently, by means of superposition, Eqs. (8-10) are used to compute $u_{Z, H S}(y)$, i.e., the HS surface deflection at the same $y_{j}$ 's:

$$
\begin{aligned}
& u_{Z, H S}(y)=\frac{\left(1-v_{H S}^{2}\right)}{2 \pi E_{H S}} \sum_{m=1}^{12} \frac{1}{b} r_{Z}\left(\frac{m L}{12}-\frac{L}{24}\right) f\left(y-\left(\frac{m L}{12}-\frac{L}{24}\right)\right) \\
& \longleftrightarrow \text { Expression I } \longleftrightarrow \text { Expression II }
\end{aligned}
$$

This equation represents the contribution of the 12 adjacent patches indexed $m=1, \ldots, 12$ with $m=1$ identifying the patch closest to the coordinate origin. With reference to Eq. 8, Expression I represents $q_{Z}$ and Expression II represents $f(y)$. Expression I gives the stress intensity at center of a $m^{\text {th }}$ patch calculated using Eq. 3; the division by $b$ implies that the stress distribution is taken as uniform across the width of the FB. Expression II is computed according to Eq. 9, with $a=L / 12$ and $b$.

The five sought $a_{i}$ 's as well as $D_{4}$ are determined by minimizing the sum of the square of the differences between the HS and FB displacements across all considered $y_{j}$ 's. The formulation is:

$$
\left(a_{i}^{*}, D_{4}^{*}\right)=\underset{a_{i}, D_{4}}{\operatorname{argmin}} \sum_{j=0}^{J}\left(u_{z, H S}\left(y_{j}\right)-u_{z, F B}\left(y_{j}\right)\right)^{2} \quad(i=1, \ldots, 5)
$$


where the optimal/final argument values are denoted with an asterisk as superscript, i.e., $a_{i}^{*}$ 's and $D_{4}^{*}$. Note that due to assumption of linearity the $a_{i}^{*}$ 's are essentially unaffected by choice of $w_{Z}$.

\section{Track Modulus Determination (a main section)}

All above-described formulations are ultimately interlinked hereafter to comprise a method for a priori track modulus determination. The calculations require all parameters to be known and fixed, with only assumption being a trial value for $k_{Z}$. The first step is to solve Eq. 12 and obtain $a_{i}^{*}$ 's that represent the interaction between a single FB supported on a HS. Next, the load applied on top of the $n^{\text {th }}$ DS, i.e., $S_{Z}^{n}$ (refer to Fig. 1) is calculated from the standard model:

$S_{Z}^{n}=\frac{s P_{Z} \beta_{Z} e^{-\beta_{Z}|n s|}}{2}\left(\cos \beta_{Z} n s+\sin \beta_{Z}|n s|\right)$

where $\beta_{Z}=\sqrt[4]{k_{Z} /\left(4 E_{I B} I_{Y, I B}\right)}$ in which $E_{I B}$ and $I_{Y, I B}$ are the Young's modulus and moment of inertia about the $Y$ axis of the IB, respectively. This expression is obtained by multiplying $s k_{Z}$ with $u_{Z, I B}^{n}$, i.e., the displacement of the IB at location corresponding to the $n^{\text {th }}$ FB (Bose et al. 2018). Here $n$ varies from $-N$ to $+N$ with $2 N+1$ denoting the total number of FBs considered in the analysis.

Then, the line-load applied on top of the $n^{\text {th }}$ FB is:

$w_{Z}^{n}=S_{Z}^{n} / L_{2}$

where $L_{2}$ signifies length of rail-pads (refer to Fig. 2). Also, the maximum IB displacement is given by:

$u_{Z, I B}^{0}=S_{Z}^{0} / s k_{Z}$

Further, the shortening of the zeroth DS is:

$\Delta u_{Z, D S}^{0}=S_{Z}^{0} / K_{Z, D S}$

where $K_{Z, D S}$ is the stiffness of DSs. 
Next, Eq. 3 is employed with $a_{i}^{*}$ 's and $w_{Z}^{n}$ replacing $a_{i}$ 's and $w_{Z}$ (respectively) to express $r_{Z}^{n}(y)$ , i.e., the support reaction distribution below the $n^{\text {th }} \mathrm{FB}$ :

$$
r_{Z}^{n}(y)=\frac{24 w_{Z}^{n} L_{2}}{L a_{T}^{*}}\left(\begin{array}{l}
\sum_{k=1}^{4}\left(a_{k}^{*}-a_{k+1}^{*}\right)(H(y-k L / 12)-H(y-L+k L / 12)) \\
+\left(a_{5}^{*}-1\right)(H(y-5 L / 12)-H(y-7 L / 12))-a_{1}^{*}
\end{array}\right)
$$

wherein $a_{T}^{*}=2\left(a_{1}^{*}+a_{2}^{*}+a_{3}^{*}+a_{4}^{*}+a_{5}^{*}+1\right)$. Note that in doing so any cross-interaction between the adjacent FBs is neglected (with respect to the foundation support stress distribution), i.e., one interaction analysis between a FB and HS is utilized for all FBs.

Subsequently, the deflection of the HS for a point located directly underneath the zeroth DS is sought - denoted by $u_{Z, H S}^{T}$. For clarifying the calculation rational, Fig. 4 offers a plan view of the HS loaded by several FBs. The point of deflection calculation is depicted in the figure at $y=L_{1}$ for $n=0$ (as a triangular marker). Obtaining $u_{Z, H S}^{T}$ requires calculating $u_{Z, H S}^{0}\left(L_{1}\right)$, i.e., evaluating Eq. 11 with $r_{Z}=r_{Z}^{0}(y)$ at $y=L_{1}$. It additionally requires computing the deflection contributed by all adjacent FBs, i.e., considering the effect from all $r_{Z}^{n}(y)$ 's excluding $n=0$. To quantify this latter contribution, it is sufficient to consider Boussinesq's point-load solution when superposing the effects from all stress patches:

$$
u_{Z, H S}^{C}=\frac{2\left(1-v_{H S}^{2}\right)}{\pi E_{H S}} \sum_{n=1}^{N} \sum_{m=1}^{12} \frac{P_{m}^{n}}{R_{m}^{n}}
$$

where,

$$
\begin{aligned}
& P_{m}^{n}=\frac{L}{12} \cdot r_{Z}^{n}\left(\frac{m L}{12}-\frac{L}{24}\right) \\
& R_{m}^{n}=\sqrt{(n s)^{2}+\left(L_{1}-\left(\frac{m L}{12}-\frac{L}{24}\right)\right)^{2}}
\end{aligned}
$$

Eq. 18 represents the deflection contribution of 12 adjacent patches indexed $m=1, \ldots, 12$ from all considered FBs excluding $n=0$. Symmetry about the model center permits considering twice the contribution of the 
FBs indexed $n=1, \ldots, N$ (hence the multiplication by 2 in Eq. 18). Both $P_{m}^{n}$ and $R_{m}^{n}$ are graphically presented in Fig. 4. As can be seen, $P_{m}^{n}$ is the force intensity at the center of the $m^{\text {th }}$ patch for the $n^{\text {th }}$ FB, and $R_{m}^{n}$ is the distance between the calculation point and the center of the $m^{\text {th }}$ patch of the $n^{\text {th }}$ FB. Thus, the sought HS deflection is given by the summation:

$$
u_{Z, H S}^{T}=u_{Z, H S}^{C}+u_{Z, H S}^{0}\left(L_{1}\right)
$$

Ultimately, by matching $u_{Z, H S}^{T}$ plus the shortening of the zeroth DS $\Delta u_{Z, D S}^{0}$ against the maximal displacement in the standard model $u_{Z, I B}^{0}$ the representative track modulus $k_{Z}^{*}$ (associated with all 3-D model attributes) is determined:

$$
u_{Z, H S}^{T}+\Delta u_{Z, D S}^{0}=u_{Z, I B}^{0} \quad \text { for } k_{Z}=k_{Z}^{*}
$$

Fig. 5 presents a flowchart that summarizes the entire method of track modulus determination. As can be seen the process commences by fixing all model parameters and an assumed/trial value for the track modulus. Then after, calculations and exchange of information take place in the standard track model and in the 3-D track model. The specific equations needed for each step are indicated in the flowchart. The final step (after which the process ends) requires solving Eq. 22, i.e., finding $k_{Z}^{*}$. This is done by improving the initial assumption for $k_{Z}$ and iterating until satisfactory convergence. Thus, a track modulus is determined, associated with the entire parameter set, and satisfying both maximal rail displacement and moment distribution along the rail.

\section{Method Illustration (a main section)}

The purpose here is to illustrate, by means of application, the proposed track modulus determination method. Some intermediate results will also be shown to further facilitate clarity of the underlying calculations. A reference set of input parameters was chosen for this purpose - shown in Table 1. As can be seen, the IB (rail) properties are taken as per UIC60, the stiffness of the DS (rail-pads) is $100 \mathrm{MN} / \mathrm{m}$, the 
FBs (sleepers) are of concrete, each $2.5 \mathrm{~m}$ long with a rectangular cross-section (base width $0.25 \mathrm{~m}$ ), spaced apart by $0.6 \mathrm{~m}$; the elastic modulus of the supporting HS is $200 \mathrm{MPa}$.

All calculations were done considering $P_{Z}=80 \mathrm{kN}$ (a choice that does not influence the final result) and 37 FBs, i.e., a central FB plus 18 FBs on each side (see Fig. 1). This latter choice was taken to guarantee that the load distribution between the sleepers was fully captured across the entire parameter range. With respect to the flowchart in Fig. 5, the FB-HS interaction was solved first (Eq. 12), giving: $a_{1}^{*}=1.94$, $a_{2}^{*}=1.69, a_{3}^{*}=1.87, a_{4}^{*}=1.56$, and $a_{5}^{*}=1.21$. Subsequently, the shortening of the zeroth DS (Eq. 16) was: $\Delta u_{Z, D S}^{0}=0.308 \mathrm{~mm}$, corresponding to $S_{Z}^{0}=30.8 \mathrm{KN}$. The HS deflection directly underneath the zeroth DS (Eq. 21) was: $u_{Z, H S}^{T}=0.440 \mathrm{~mm}$ of which about $35 \%$ was from $u_{Z, H S}^{C}$ (Eq. 18). Finally, the sought track modulus was obtained by matching the maximal IB displacement $u_{Z, I B}^{0}$ (Eq. 15) with $u_{Z, H S}^{T}+\Delta u_{Z, D S}^{0}=0.748 \mathrm{~mm}$. The result was: $k_{Z}^{*}=68.7 \mathrm{MPa}$. It is noted that the $a_{i}^{*}$ 's above indicate a maximum contact stress to be occurring near the edges of the FB; this is in contrast to the accepted viewpoint that the peak stresses occur below the rails (e.g., Zakeri and Sadeghi, 2007). This is the consequence of the assumption of a FB in contact with an elastic continuum, which mandates high stresses at the edges to fulfill deformation compatibility.

Additionally, a parametric investigation was conducted to study the behavior of $k_{Z}^{*}$. For this purpose the following parameter values were varied: FB spacings, half-space modulus $E_{H S}$ and discrete spring stiffness $K_{Z, D S}$. The chosen range for these parameters is also shown in Table 1. All other parameters (within a realistic range) were noticed to have minor influence on track modulus and therefore remained fixed at their reference value.

The results of this investigation are presented in Fig. 6 which depicts track modulus vs. half-space modulus for five different rail-pad stiffnesses and two different sleeper spacings. Fig. 6(a) and Fig. 6(b) refer to $s=0.6 \mathrm{~m}$ and $s=0.5 \mathrm{~m}$ respectively. In both figures each line represents the variation of $k_{Z}^{*}$ with 


\section{Summary, Conclusions, and Comments}

This paper offered a new method for a priori determination of track modulus based on elastic solutions. Within an analytical framework, a 3-D model was developed (Fig. 1(b)), capable of representing a wide range of track-types, in terms of components and materials that underlay the rails. Closed form equations were presented for calculating displacements of a finite beam subjected to two line loads and non-uniform support reaction, and calculating surface deflection of a half-space loaded over a rectangular stress patch. These equations were subsequently utilized to determine track modulus by linking the 3-D model and the standard track model of infinite beam on springs (Fig. 1(a)). The linkage was based on simultaneous equivalency of both maximal displacement as well as force distribution along the rail. A flowchart was 
introduced to summarize the main calculation steps (Fig. 5). Overall, the method is deemed flexible and robust, while at the same time computationally 'lightweight' and straightforward to reproduce.

Track modulus determination was demonstrated via application of the method to a realistic set of input values. To better clarify the approach, intermediate calculation steps as well as final results were shown. The demonstration included a parametric investigation, in which the sensitivity of track modulus to the elastic modulus of the half-space, stiffness of rail-pads, and sleeper spacing was studied (Fig. 6). Results are deemed realistic and valid overall, given that they are similar in magnitude and exhibit similar sensitivity to varying input parameters when compared to GEOTRACK (Selig and Li 1994). Specifically, it was possible to closely reproduce the track modulus results shown in Figure 4 in Selig and Li for the entire range of subgrade moduli, fastener stiffnesses, and tie spacings - when assuming ballast and subballast moduli were same as subgrade to accommodate homogenous half-space assumption. Also, the results are within the range of track modulus values observed in field studies (Norman et al. 2004; Narayanan et al. 2004). A graphical depiction of these comparisons is provided in Figure 7.

The development included simplifying assumptions, some of which can be partially relieved to further enhance the applicability of the method. The treatment of all soil-like materials and track components as linear is not realistic, e.g., loading magnitude is known to affect track modulus determined in the field. Nonetheless, the linear treatment can be utilized to approximate nonlinear behavior by choosing elastic constants such that they reflect the anticipated load level. The treatment of the sleepers as beams with zero compressibility and constant geometry can also be made more realistic. Whenever the vertical compression of the sleepers (FBs) is not negligible, e.g., in the case of wooden sleepers, an additional linear spring can be assumed connected (in series) to the discrete springs representing the rail-pads. Thus, the entire calculation procedure remains unchanged except that the new shortening/flexibility is added to the left-hand-side of Eq. 22. Finally, the issue of sleepers with variable cross-section can be addressed by converting the actual dimensions to equivalent constant dimensions. In this connection, the FB length $(L)$ can be taken as the actual length of the sleeper, and the FB width $(b)$ can be obtained from dividing the 
actual sleeper base-area by $L$. Regarding the inertia moment, the following formula - based on equivalency of bending strain energy - is suggested for calculating $I_{X, F B}$ :

$$
I_{X, F B}=\frac{\int_{0}^{L} M^{2}(y) d y}{\int_{0}^{L} \frac{M^{2}(y)}{I_{X, S L}(y)} d y}
$$

where $M(y)$ is the bending moment at a distance $y$ for a FB as shown in Fig. 2, considering an arbitrary $w_{Z}$ and all $a_{i}$ 's taken as unity; and $I_{X, S L}(y)$ denotes the actual moment of inertia, which varies along the sleeper length.

In future studies, the method proposed herein can be extended to determine track modulus in the longitudinal and lateral directions. Moreover, by means of the elastic-viscoelastic correspondence principle (e.g., Schapery, 1965) the modeling approach can be enhanced to include time-dependence and thermal sensitivity of components and materials. This will facilitate, for example, a priori determination of track modulus for asphalt overlayment solutions across different train speeds and environmental conditions.

\section{Acknowledgement}

The support from Innovation Fund Denmark is gratefully acknowledged. This study is part of 'Roads2Rails: Innovative and cost-effective asphalt based railway construction system' (Grand Solutions 5156-00006B). 


\section{References}

Adegoke, C. W., Chang, C. S., and Selig, E. T. (1979). "Study of Analytical Models for Track Support Systems." Transportation Research Record, Vol. 733,pp. 12-20.

American Railway Engineering and Maintenance-of-Way Association, AREMA Manual, 2006.

Barden, L. (1962). "Distribution of Contact Pressure Under Foundations.” Géotechnique, Vol. 12, No 3, pp. 181-198, DOI: 10.1680/geot.1962.12.3.181.

Biot, M. A. (1937). "Bending of Infinite Beam on Elastic Foundation.” Journal of Applied Mechanics, Vol. 4, No. 1, pp. 1-7.

Bose, T., Levenberg, E., and Zania, V. (2018). "Analyzing Track Responses to Train Braking." Proceedings of the Institution of Mechanical Engineers, Part F: Journal of Rail and Rapid Transit, Vol. 232, No. 7, pp. 1984-1993, DOI: 10.1177/0954409718761242.

Burmister, D. M. (1945). “The General Theory of Stresses and Displacements in Layered Systems.” Journal of Applied Physics, Vol. 16, pp. 89-94 (Part I), pp. 126-127 (Part II), pp. 296-302 (Part III), DOI: /10.1063/1.1707590.

Cai, Z., Raymond, G. P., and Bathurst, R. J. (1994). "Estimate of Static Track Modulus Using Elastic Foundation Models.” Transportation Research Record, Vol. 1470, pp. 65-72.

Chang, C. S., Adegoke, C. W., and Selig, E. T. (1980). "GEOTRACK Model for Railroad Track Performance." Journal of the Geotechnical Engineering Division, Vol. 106, No. 11, pp. 1201-1218.

Daloglu, A. T., and Vallabhan, C. V. G. (2000). "Values of k for Slab on Winkler Foundation.” Journal of Geotechnical and Geoenvironmental Engineering, Vol. 126, No. 5, pp. 463-471, DOI: 10.1061/(ASCE)1090-0241(2000)126:5(463).

Ebersöhn, W., Trevizo, M. C., and Selig, E. T. (1993). "Effect of Low Track Modulus on Track Performance." In Proceedings of the Fifth International Heavy Haul Conference, International Heavy Haul Association, Virginia Beach, VA, pp. 379-388.

Galin, L. A. (1943). "On the Winkler-Zimmermann Hypothesis for Beams." Journal of Applied Mathematics and Mechanics, Vol. 7, No. 4, pp. 293-300.

Hay, W. W. (1982). Railroad Engineering. John Wiley and Sons, New York. 
Hemsley, J. A. (2000). Design Applications of Raft Foundations. Thomas Telford, London.

Ioannides, A. M. (2006). “Concrete Pavement Analysis: The First Eighty Years.” International Journal of Pavement Engineering, Vol. 7, No. 4, pp. 233-249, DOI: 10.1080/10298430600798481.

Kerr, A. D. (2003). Fundamentals of Railway Track Engineering. Simmons-Boardman Books, Omaha, Nebraska.

Kerr, A. D. (2000). “On the Determination of the Rail Support Modulus k.” International Journal of Solids and Structures, Vol. 37, pp. 4335-4351, DOI: 10.1016/S0020-7683(99)00151-1.

Khazanovich, L., Tayabji, S. D., and Darter, M. I. (2001). “Backcalculation of Layer Parameters for LTPP Test Sections, Volume I: Slab on Elastic Solid and Slab on Dense-Liquid Foundation Analysis of Rigid Pavements.” Technical Report no. FHWA-RD-00-086. FHWA, McLean, Virginia.

Klar, A., Vorster, T. E. B., Soga, K., and Mair, R. J. (2005). "Soil-Pipe Interaction due to Tunnelling: Comparison between Winkler and Elastic Continuum Solutions.” Géotechnique, Vol. 55, No. 6, pp. 461466, DOI: 10.1680/geot.2005.55.6.461.

Lee, K. M., Hou, X. Y., Ge, X. W., and Tang, Y. (2001). “An Analytical Solution for a Jointed ShieldDriven Tunnel Lining." International Journal of Numerical and Analytical Methods in Geomechanics, Vol. 25, pp. 365-390, DOI: 10.1002/nag.134.

Lu, S., Arnold, R., Farritor, S., Fateh, M., and Carr, G. (2008). "On the Relationship between Load and Deflection in Railroad Track Structure.” In Proceedings of the AREMA Annual Conference, Salt Lake City, USA.

Mair, R. J. (2008). “Tunnelling and Geotechnics: New Horizons.” Geotechnique, Vol. 58, No. 9, pp. 695736, DOI: 10.1680/geot.2008.58.9.695.

Mishra, D., Sharma, S., Shrestha, A., Li, D., and Basye, C. (2016). "GEOTRACK-2015: An Upgraded Software Tool for Railroad Track Analysis.” In Joint Rail Conference American Society of Mechanical Engineers, South Carolina, USA..

Nafari, S. F., Gül, M., and Cheng, J. R. (2017). "Quantifying Live Bending Moments in Rail Using TrainMounted Vertical Track Deflection Measurements and Track Modulus Estimations." Journal of Civil Structural Health Monitoring, Vol. 7, No. 5, pp. 637-643, DOI: 10.1007/s13349-017-0248-1. 
Narayanan, R. M., Jakub, J. W., Li, D., and Elias, S. E. (2004). "Railroad Track Modulus Estimation Using Ground Penetrating Radar Measurements.” NDT \& E International, Vol. 37, No. 2, pp. 141-151, DOI: 10.1016/j.ndteint.2003.05.003.

Newton, S. G., and Clark, R. A. (1979). "An Investigation into the Dynamic Effects on the Track of Wheelflats on Railway Vehicles." Journal of Mechanical Engineering Science, Vol. 21, No. 4, pp. 287297, DOI: 10.1243/JMES_JOUR_1979_021_046_02.

Norman, C., Farritor, S., Arnold, R., Elias, S. E. G., and Fateh, M. (2004). "Design of a System to Measure Track Modulus from a Moving Railcar.” In Proceeding of International Conference of Railway Engineering, Engineering Technics Press, London.

Poulos, H. G., and Davis, E. H. (1991). Elastic Solutions for Soil and Rock. Center for Geotechnical Research, University of Sydney.

Prause, R. H., and Kennedy, J. C. (1977). Parametric Study of Track Response. Report DOT-TSC-FRA77-75. U.S. Department of Transportation, Washington, D.C.

Rajani, B., Zhan, C., and Kuraoka, S. (1996). "Pipe-Soil Interaction Analysis of Jointed Water Mains." Canadian Geotechnical Journal, Vol. 33, No. 3, pp. 393-404, DOI: 10.1139/t96-061.

Read, D., Chrismer, S., Ebersöhn, W., and Selig, E. T. (1994). “Track Modulus Measurements at the Pueblo Soft Subgrade Site.” Transportation Research Record, Vol. 1470, pp. 55-64.

Roghani, A., and Hendry, M. T. (2017). "Quantifying the Impact of Subgrade Stiffness on Track Quality and the Development of Geometry Defects." Journal of Transportation Engineering Part A: Systems, Vol. 143, No. 7, pp. 1-10, DOI: 10.1061/JTEPBS.0000043.

Sadeghi, J., and Barati, P. (2010). "Improvements of Conventional Methods in Railway Track Analysis and Design.” Canadian Journal of Civil Engineering, Vol. 37, No. 5, pp. 675-683, DOI: 10.1139/L10-010.

Schapery, R. A. (1965). “A Method of Viscoelastic Stress Analysis using Elastic Solutions.” Journal of the Franklin Institute Vol. 279, No. 4, pp. 268-289.

Setiadji, B. H., and Fwa, T. F. (2009). "Examining k-E Relationship of Pavement Subgrade Based on LoadDeflection Consideration.” Journal of Transportation Engineering, Vol. 135, No. 3, pp. 140-148. 
Selig, E. T., and Waters, J. M. (1994). Track Geotechnology and Substructure Management. Thomas Telford Services Ltd, London.

Selig, E. T., and Li, D. (1994). “Track Modulus: Its Meaning and Factors Influencing It.” Transportation Research Record, Vol. 1470, pp. 47-54.

Stewart, H. E. (1985). "Measurement and Prediction of Vertical Track Modulus.” Transportation Research Record, Vol. 1022, pp. 65-71.

Steinbrenner, W. A. (1936). “A Rational Method for Determination of the Vertical Normal Stresses under Foundations." In Proceedings of the first international conference on soil mechanics and foundation engineering, Vol. 2: pp. 142-143.

Terzaghi, K. (1955). "Evaluation of Coefficients of Subgrade Reaction.” Geotechnique, Vol. 5, No. 4, pp. 41-50.

Tzanakakis, K. (2013). “The Effect of Track Stiffness on Track Performance.” The Railway Track and Its Long Term Behaviour, STTT 2, 79-87, DOI:10.1007/978-3-642-36051-0_16.

Unified Facilities Criteria (2004). Railroad design and rehabilitation, Report UFC 4-860-01FA.

Vesić, A. B. (1961). "Beams on Elastic Subgrade and Winkler's Hypothesis." In Proceedings of the 5th International Conference on Soil Mechanics and Foundation Engineering, Paris, pp. 845-850.

Vesic, A. S., and Saxena S. K. (1969). “Analysis of Structural behavior of Road Test Rigid Pavement.” Highway Research Record, Vol. 291, pp. 156-158.

Winkler, E. (1867). Die Lehre von der Elasticität und Festigkeit mit besonderer Rücksicht auf ihre Anwendungen in der Technik. Theil. H Dominicus, Vol. 1, Prag.

Westergaard, H. M. (1948). “New Formulas for Stresses in Concrete Pavements of Airfields.” Transactions of the American Society of Civil Engineers, Vol. 113, pp. 425-439.

Wood, A. M. M. (1975). “The Circular Tunnel in Elastic Ground.” Géotechnique, Vol. 25, No. 1, pp. 115127, DOI: 10.1680/geot.1975.25.1.115. 
Zakeri, J. A., and Abbasi, R. (2012). "Field Investigation on Variation of Rail Support Modulus in Ballasted Railway Tracks." Latin American Journal of Solids and Structures, Vol. 9, No. 6, pp. 643-656, DOI: 10.1590/S1679-78252012000600002.

Zakeri, J.A. and Sadeghi, J. (2007). "Field Investigation on Load Distribution and Deflections of Railway Track Sleepers.” Journal of Mechanical Science and Technology, Vol. 21, pp. 1948-1956. 
Table 1. Input Parameters for Method Illustration

\begin{tabular}{|c|c|c|c|c|c|c|}
\hline Component & Parameter/Role & Symbol & Units & $\begin{array}{l}\text { Reference } \\
\text { Value }\end{array}$ & Range & Comments \\
\hline \multirow{2}{*}{$\begin{array}{c}\text { Infinite Beam } \\
\text { (IB) }\end{array}$} & $\begin{array}{l}\text { Moment of inertia } \\
\text { about } Y \text { axis }\end{array}$ & $I_{Y, I B}$ & $\mathrm{~m}^{4}$ & $3.04 \times 10^{-5}$ & - & \multirow{2}{*}{$\begin{array}{l}\text { UIC } 60 \text { rail } \\
\text { section }\end{array}$} \\
\hline & Young's modulus & $E_{I B}$ & $\mathrm{GPa}$ & 208 & - & \\
\hline \multirow[t]{5}{*}{$\begin{array}{l}\text { Discrete Spring } \\
\text { (DS) }\end{array}$} & Stiffness & $K_{Z, R P}$ & $\mathrm{MN} / \mathrm{m}$ & 100 & $\begin{array}{c}25 \text { to } \\
250\end{array}$ & Rail-pad stiffness \\
\hline & $\begin{array}{c}\text { Moment of inertia } \\
\text { about } X \text { axis }\end{array}$ & $I_{X, F B}$ & $\mathrm{~m}^{4}$ & $1.22 \times 10^{-4}$ & - & - \\
\hline & Young's modulus & $E_{F B}$ & $\mathrm{GPa}$ & 30 & - & Concrete Sleeper \\
\hline & Length & $L$ & $\mathrm{~m}$ & 2.50 & - & \multirow{2}{*}{$\begin{array}{l}\text { Sleeper length } \\
\text { Sleeper base } \\
\text { width }\end{array}$} \\
\hline & Base width & $b$ & $\mathrm{~m}$ & 0.25 & - & \\
\hline \multirow{5}{*}{$\begin{array}{l}\text { Finite Beam } \\
\text { (FB) }\end{array}$} & $\begin{array}{l}\text { Total number on } \\
\text { one side }\end{array}$ & $N$ & - & 18 & - & See Eq. 18 \\
\hline & Spacing & $s$ & $\mathrm{~m}$ & 0.60 & $\begin{array}{c}0.50 \text { or } \\
0.60\end{array}$ & See Fig. 1 \\
\hline & Position of $w_{Z}$ & $L_{1}$ & $\mathrm{~m}$ & 0.50 & - & See Fig. 2 \\
\hline & $\begin{array}{l}\text { Length over which } \\
\qquad w_{Z} \text { operates }\end{array}$ & $L_{2}$ & $\mathrm{~m}$ & 0.17 & - & Rail-pad length \\
\hline & $\begin{array}{l}\text { No. of matching } \\
\text { FB-HS points }\end{array}$ & $J$ & - & 50 & - & Eq. 12 \\
\hline \multirow{2}{*}{$\begin{array}{l}\text { Half-space } \\
\quad \text { (HS) }\end{array}$} & Young's modulus & $E_{H S}$ & $\mathrm{MPa}$ & 200 & $\begin{array}{c}20 \text { to } \\
300\end{array}$ & \multirow{2}{*}{$\begin{array}{l}\text { All soil-like } \\
\text { materials }\end{array}$} \\
\hline & Poisson's ratio & $v_{H S}$ & - & 0.30 & - & \\
\hline
\end{tabular}




\section{List of Figures}

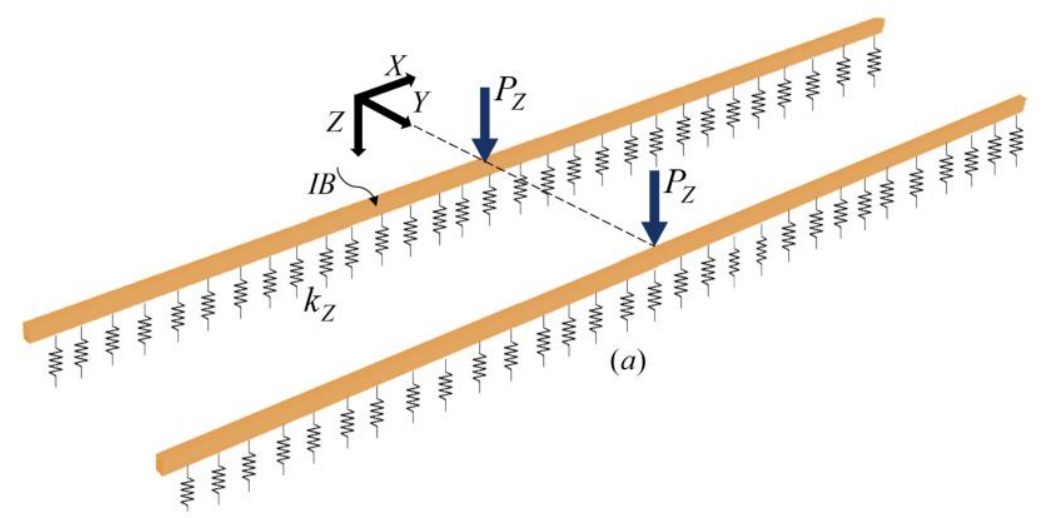

Figure 1. A sketch depicting the models considered for track modulus determination (a) standard model (b) elastic 3-D model. 
2

3

4

5

6

10

11

12

13

14

15

16

17

18

19

20

21

22

23

24

25

26

27

28

29

30

31

32

33

34

35

36

37

38

39

40

41

42

43

44

45

46

47

48

49

50

51

52

53

54

55

56

57

58

59

60

61

62

63

64

65

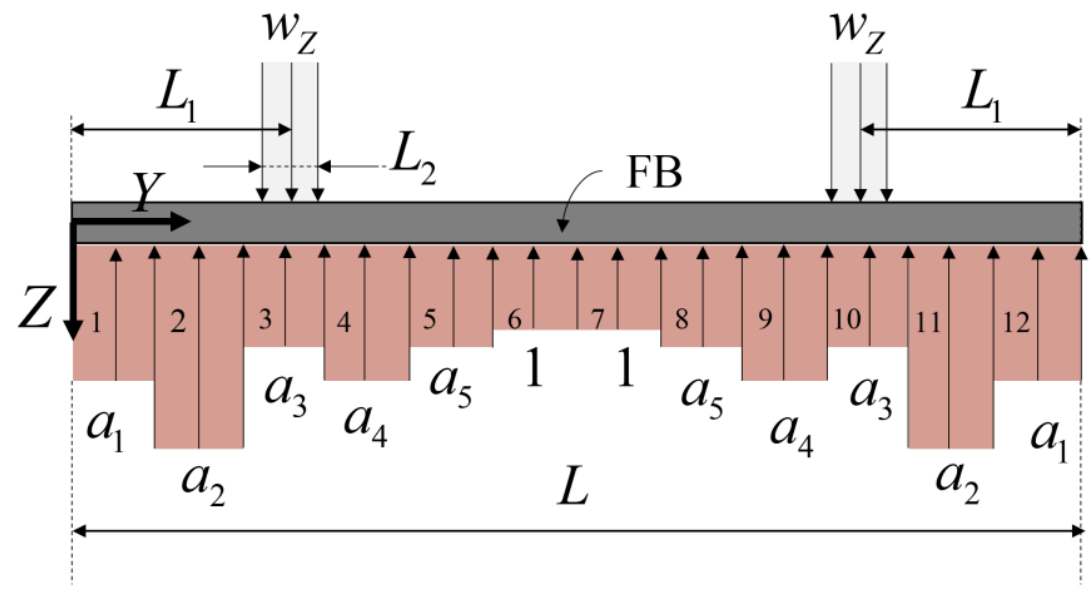

Figure 2. A finite beam subjected to two line-loads and a non-uniform support reaction. 


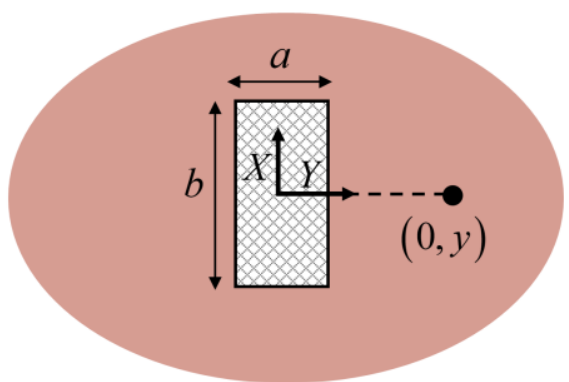

(a)

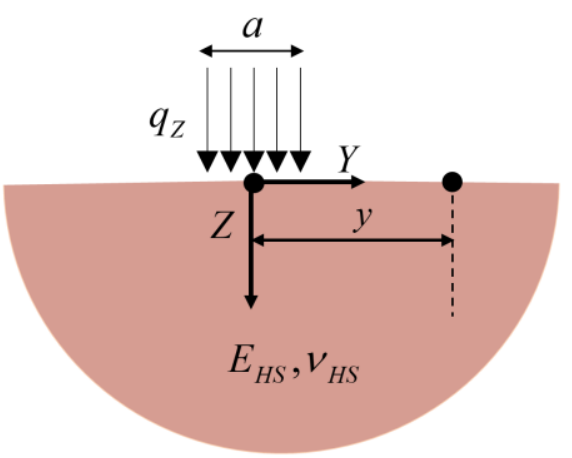

(b)

Figure 3. An elastic half-space loaded over a rectangular stress patch: (a) top view, and (b) cross-sectional view. 


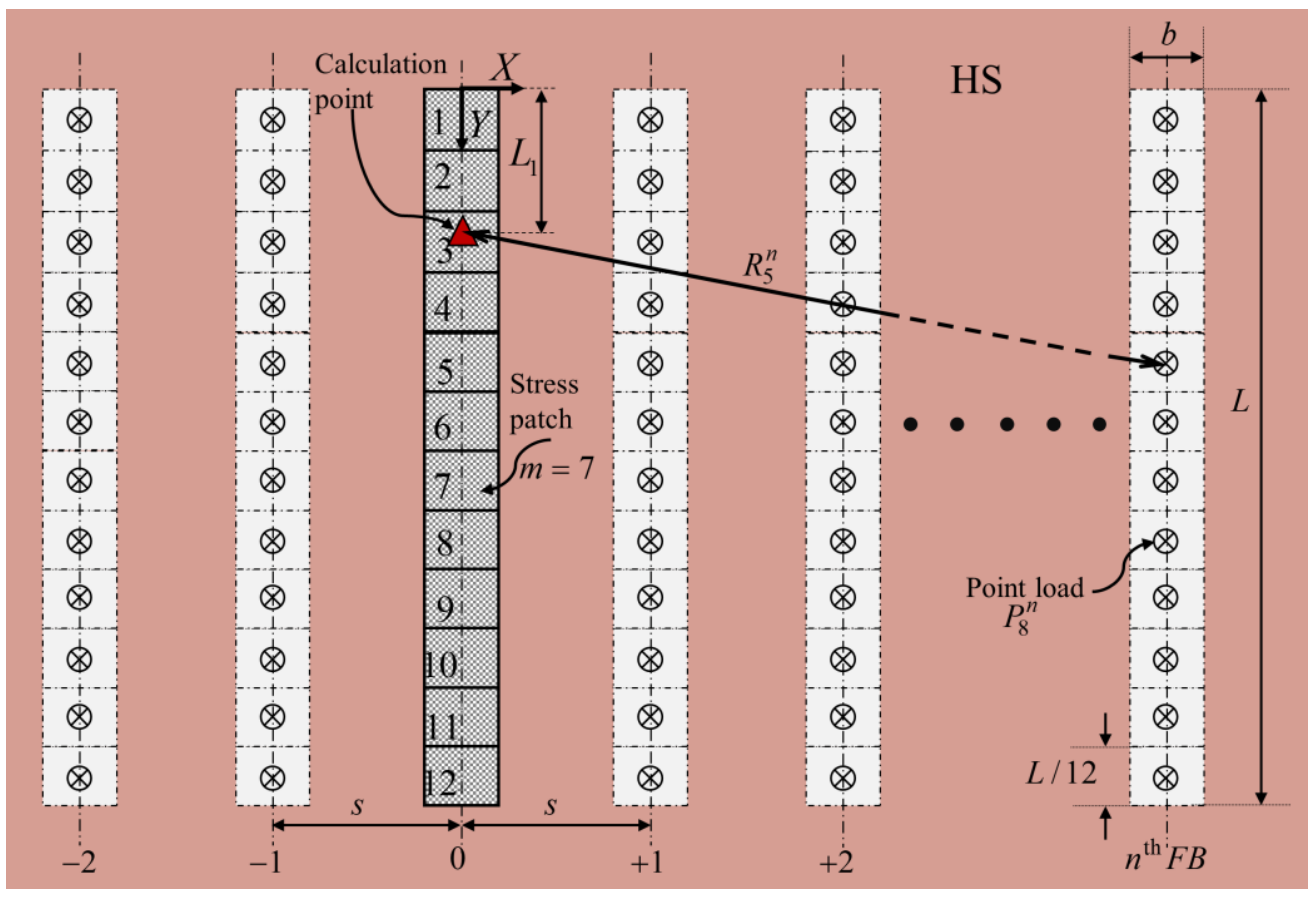

Figure 4. Top view of an elastic half-space loaded by stress patches and point forces representing the support-interaction of several finite beams. 


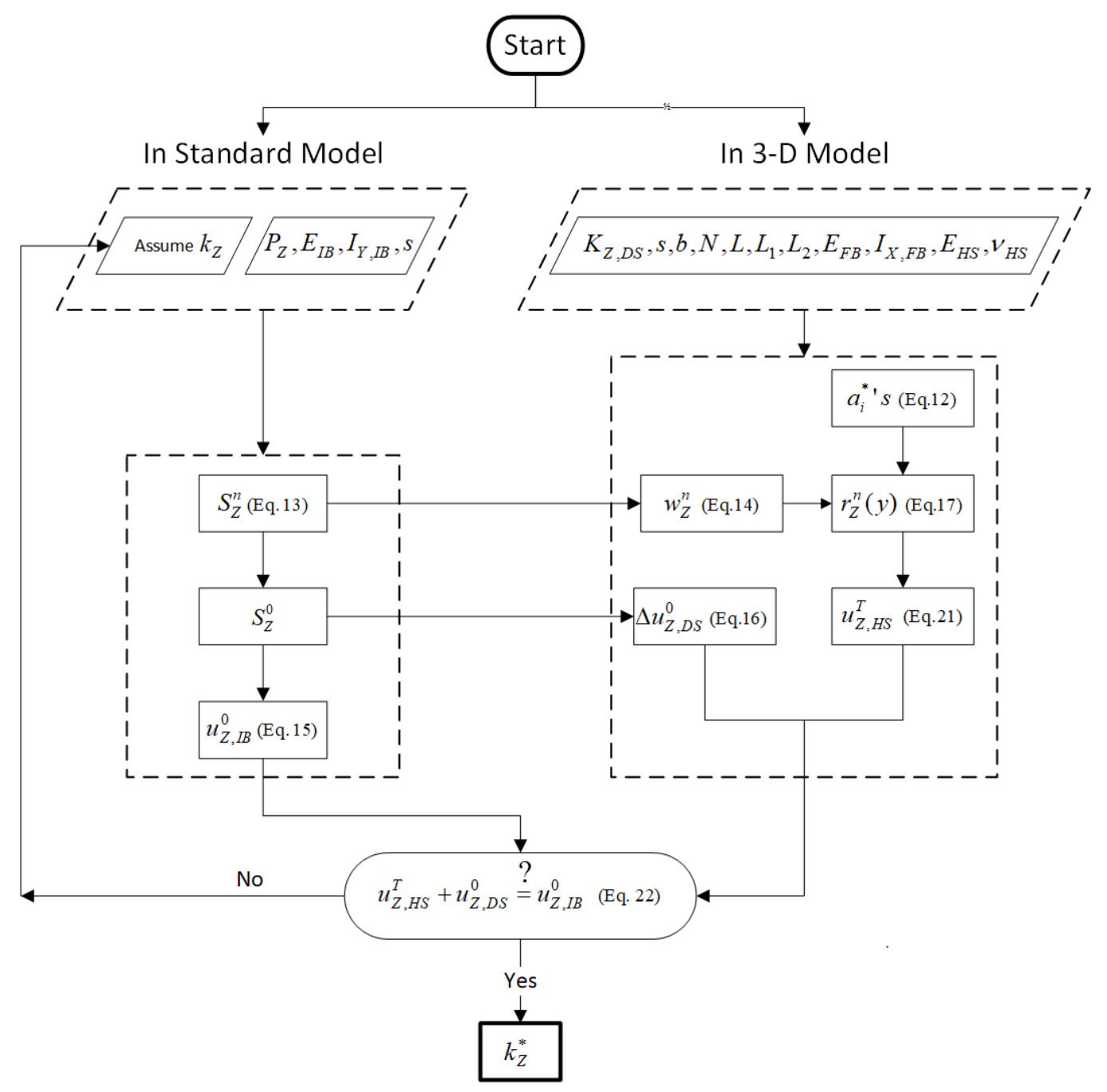

Figure 5. Flowchart describing the proposed track modulus determination method. 


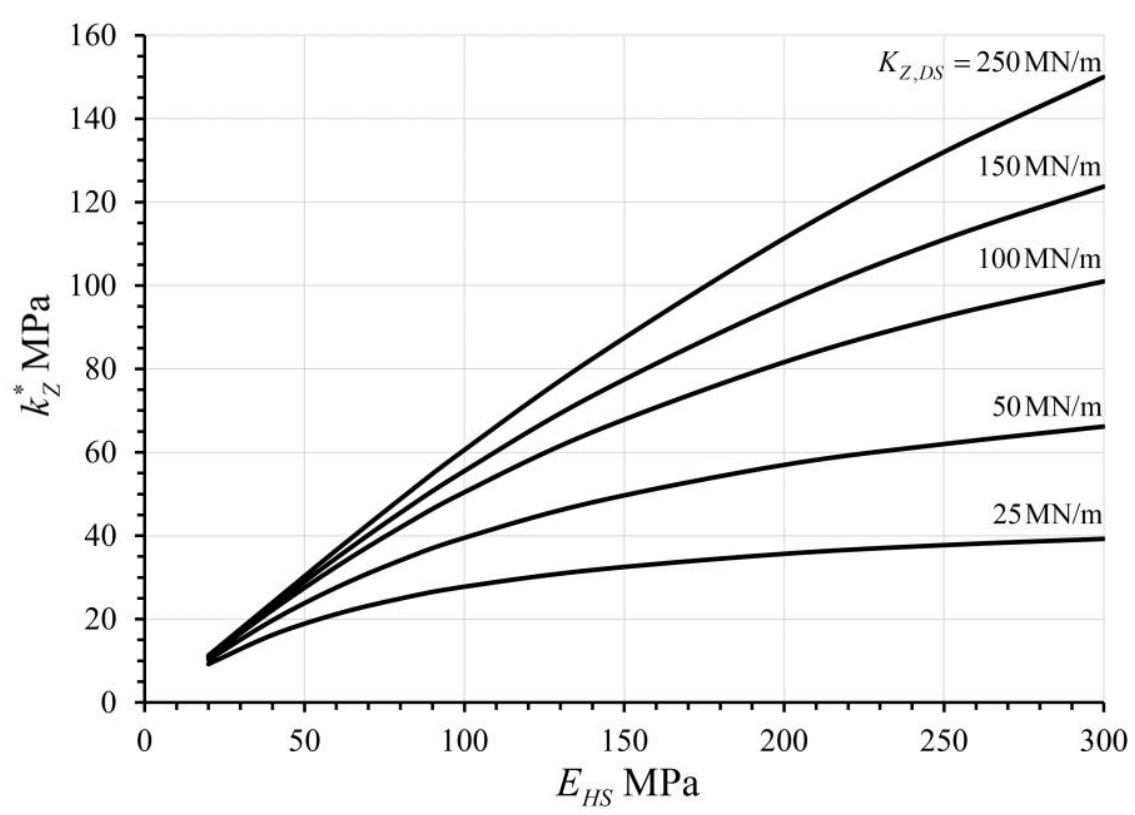

(b)

Figure 6. Track modulus determined as a function of half-space modulus for different rail-pad stiffnesses and sleeper spacings based on Table 1 parameters: (a) $s=0.6 \mathrm{~m}$, and (b) $s=0.5 \mathrm{~m}$. 
Figure 7. A priori determined track modulus values compared with track modulus values from other sources for different model parameters (numbers in the figure represent the lower bound, the nominal value and the upper bound of the parameters as per Selig and Li 1994). 


\section{KSCE-D-19-00372}

\section{A Priori Determination of Track Modulus Based on Elastic Solutions}

Response to reviewer comments. The reviewers are hereby thanked for their efforts in studying the manuscript and for their thoughtful comments and recommendations. A sincere attempt was made to address these by adding and thereby improving the paper. Provided below are itemized responses to the individual comments.

\section{Reviewer \#2 comments and authors responses}

C1.1) The authors added and modified well according to the previous comments. The reviewer suggests one more recommendation and modification. In chapter 6, authors insisted that their own method is wellmatched to the result of GEOTRACK, Norman et al. 2004, Zakeri and Abbasi 2012 and Narayanan et al. 2004. Actually the reader cannot check how it is matched. If you add some more comparison figures or tables, it would be helpful. Newly added reference (Tzanakakis, K. (2013).) is mispositioned.

To address this comment, a new figure (Figure 7) has been added to the paper showing a comparison of track modulus values, calculated using the current method and with the reference studies. The Figure has also been referred to in the text in Chapter 6 as:

"Specifically, it was possible to closely reproduce the track modulus results shown in Figure 4 in Selig and Li for the entire range of subgrade moduli, fastener stiffnesses, and tie spacings - when assuming ballast and subballast moduli were same as subgrade to accommodate homogenous half-space assumption. Also, the results are within the range of track modulus values observed in field studies (Norman et al. 2004; Narayanan et al. 2004). A graphical depiction of these comparisons is provided in Figure 7.

The reference (Tzanakakis, K. (2013) position has been rectified.

New Figure 7 and caption: 


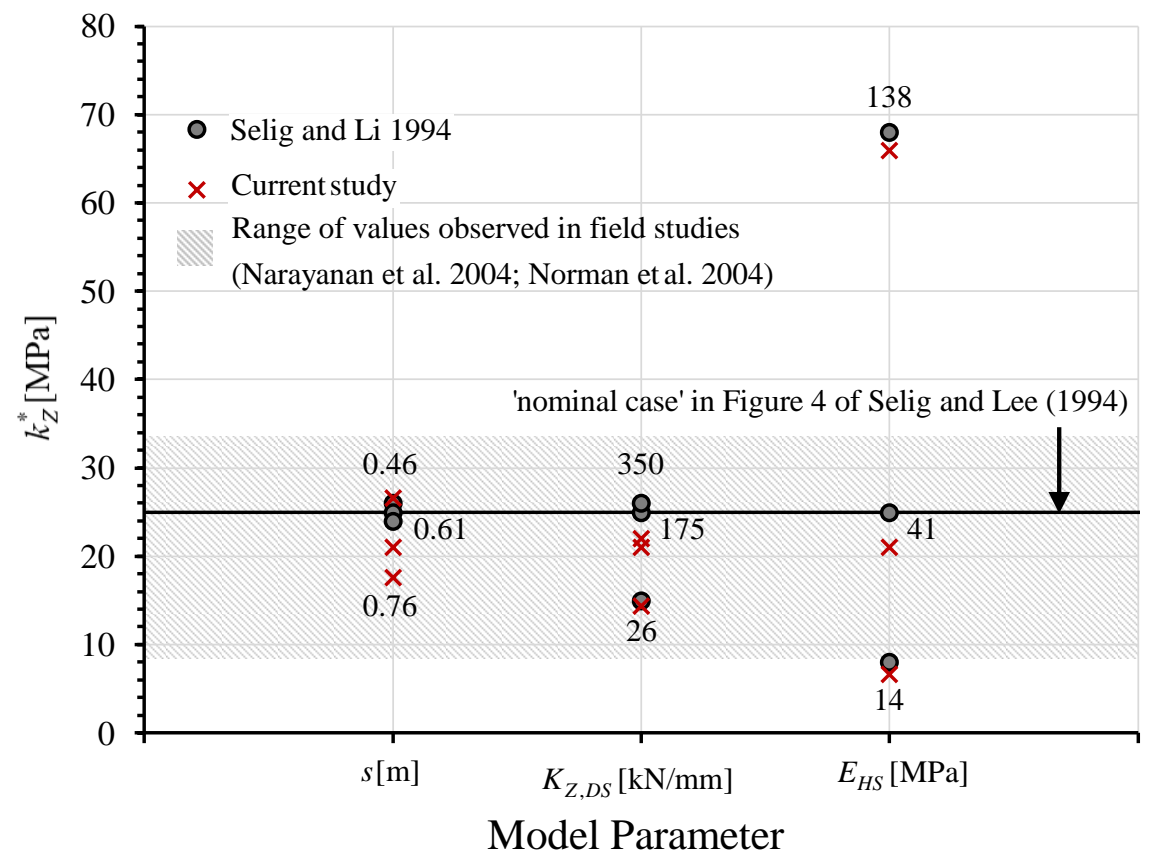

Figure 7. A priori determined track modulus values compared with track modulus values from other sources for different model parameters (numbers in the figure represent the lower bound, the nominal value and the upper bound of the parameters as per Selig and Li 1994). 


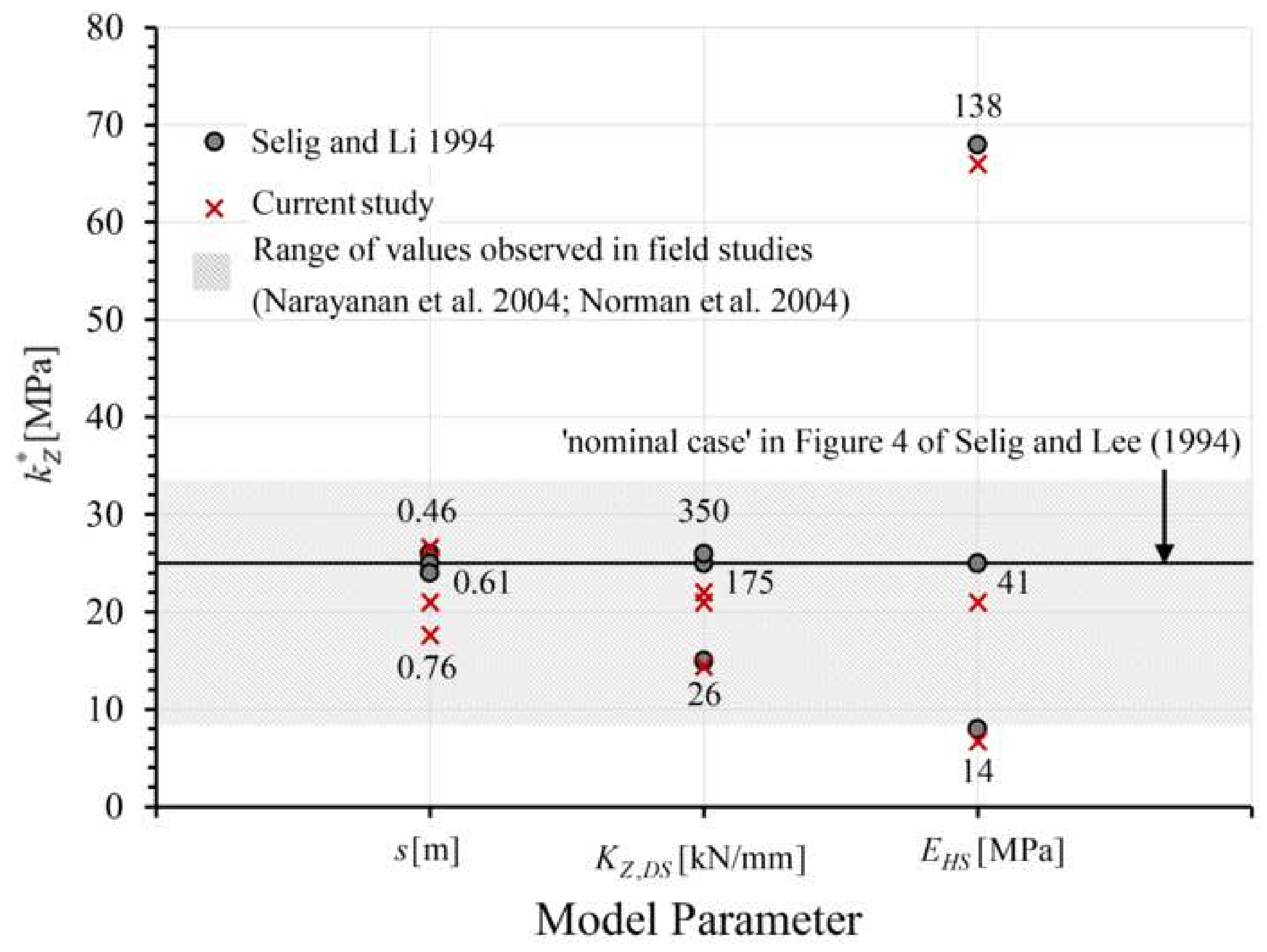

